Pacific Journal of Mathematics

THE OPEN MAPPING THEOREM FOR SPACES WITH UNIQU 


\title{
THE OPEN MAPPING THEOREM FOR SPACES WITH UNIQUE SEGMENTS
}

\author{
JAMES D. Stein, JR.
}

If $X$ and $Y$ are spaces with unique segments, an affine map from $X$ into $Y$ is a map which takes segments into segments. The purpose of this paper is to give conditions on spaces $X$ and $Y$ such that we can prove the following versions of the Open Mapping and Closed Graph Theorems: (1) a continuous affine map of $X$ onto $Y$ is open, and (2) an affine map of $X$ onto $Y$ with closed graph is continuous.

Let $X$ and $Y$ be spaces with unique segments, with $\Phi(x, y, t)$ $(0 \leqq t \leqq 1)$ denoting the intrinsically parametrized segment from $x$ to $y$. A map $T$ between two such spaces is said to be affine if $T(\Phi(x, y, t))=$ $\Phi(T x, T y, t)$, and a subset $A$ is convex if $x, y \in A, 0 \leqq t \leqq 1 \Rightarrow \Phi(x, y, t) \in$ $A$. The purpose of this paper is to prove versions of the Open Mapping and Closed Graph theorems for classes of spaces with unique segments.

Throughout this paper, all metric spaces will be spaces with unique segments (unique curves of minimal, realizing the distance, length between any two points). The open sphere with center $x$ and radius $\varepsilon$ will be denoted by $S(x, \varepsilon)$.

Definition 1. $(X, d)$ is said to be regular if it is complete, the closure of convex sets is convex, open spheres are convex, and $x_{n} \rightarrow$ $x_{0} \Rightarrow \Phi\left(z, x_{n}, \alpha\right) \rightarrow \Phi\left(z, x_{0}, \alpha\right)$ for $z \in X, \alpha \in[0,1]$.

Definition 2. A sphere $S\left(x_{0}, \varepsilon\right)$ is said to be thick if for any $y \in S\left(x_{0}, \varepsilon\right)$ and $x \in X, x \neq y$, there is a $z \in S\left(x_{0}, \varepsilon\right)$ and $\alpha \in(0,1]$ such that $y=\Phi(z, x, \alpha)$.

It is always possible to extend geodesics into thick spheres.

Definition 3. A sphere $S\left(x_{0}, \varepsilon\right)$ is said to be round if, given $x \in$ $S\left(x_{0}, \varepsilon\right), y \in S\left(x, \varepsilon-d\left(x_{0}, x\right)\right)$, and $\lambda$ such that $d(x, y)<\lambda<\varepsilon-d\left(x_{0}, x\right) \Rightarrow$ there is a $z \in S\left(x, \varepsilon-d\left(x_{0}, x\right)\right)$ and $\alpha \in(0,1)$ such that $d(x, z)=\lambda, y=$ $\Phi(x, z, \alpha)$.

Given any sphere $S(x, \delta)$ contained in a round sphere $S\left(x_{0}, \varepsilon\right)$ and any $y \in S(x, \delta), y$ lies on a geodesic connecting $x$ and a point in $S(x, \delta)$ whose distance from $x$ is arbitrarily close to $\delta$. It should be noted that both thickness and roundness are hereditary properties; that is, if $S\left(x_{0}, \varepsilon\right)$ is thick (round) and $S(x, \delta) \subseteq S\left(x_{0}, \varepsilon\right)$ then $S(x, \delta)$ is thick (round).

We now prove an Open Mapping theorem. 
THEOREM 1. Let $(X, d)$ and $\left(X, d^{\prime}\right)$ be regular, and assume that each point in $X$ is the center of a thick sphere, and each point in $Y$ is the center of a round sphere. Assume further that, for each open $U \subseteq Y, y \in Y$ and $\alpha \in(0,1]$, the set $\{\Phi(y, u, \alpha) \mid u \in U\}$ is open. Let $T$ be continuous affine map of $X$ onto $Y$. Then $T$ is open.

Proof. Let $U$ be an open subset of $X$, let $x_{0} \in U$, and let $\varepsilon>0$ such that $S\left(x_{0}, \varepsilon\right)$ is thick and a subset of $U$. Let $U_{k}=S\left(x_{0}, k\right), k=$ $1,2, \cdots$; since $T$ is into, $Y=\bigcup_{k=1}^{\infty} \overline{T\left(U_{k}\right)}$. By the Baire Category Theorem, some $\overline{T\left(U_{k}\right)}$ contains an $S\left(T x^{\prime}, \varepsilon^{\prime}\right)$. Since $U_{k}$ is convex and $T$ is affine, $T\left(U_{k}\right)$ is convex, and so $\overline{T\left(U_{k}\right)}$ is convex. Since thickness is hereditary, we can assume $\varepsilon<k$. Choose $x \in S\left(x_{0}, \varepsilon\right)$ and $\alpha \in(0,1]$ with $x_{0}=\Phi\left(x, x^{\prime}, \alpha\right)$; letting $z=T x$ we have $T x_{0}=\Phi\left(z, T x^{\prime}, \alpha\right)$, and $z \in \overline{T\left(U_{k}\right)}$. Now $T x_{0} \in\left\{\Phi(z, u, \alpha) \mid u \in S\left(T x^{\prime}, \varepsilon^{\prime}\right)\right\}$, which is open by hypothesis and also a subset of $\overline{T\left(U_{k}\right)}$. We can therefore find a round sphere $S\left(T x_{0}, \varepsilon^{\prime \prime}\right) \subset \overline{T\left(U_{k}\right)}$.

If $d^{\prime}\left(y, T x_{0}\right)<\varepsilon^{\prime \prime}$, let $\gamma=1 / 2\left(\varepsilon^{\prime \prime}+d^{\prime}\left(y, T x_{0}\right)\right)$; since $S\left(T x_{0}, \varepsilon^{\prime \prime}\right)$ is round and $\gamma<\varepsilon^{\prime \prime}$, there is a $z \in S\left(T x_{0}, \varepsilon^{\prime \prime}\right)$ with $d^{\prime}\left(z, T x_{0}\right)=\gamma$ and $y=$ $\Phi\left(T x_{0}, z, \alpha\right)$, clearly $\alpha=\gamma^{-1} d^{\prime}\left(y, T x_{0}\right)$. Now $z \in \overline{T\left(U_{k}\right)}$, so choose $\left\{x_{n} \mid n=\right.$ $1,2, \cdots\}$ with $d\left(x_{0}, x_{n}\right)<k$ and $T x_{n} \rightarrow z$; let $z_{n}=\Phi\left(x_{0}, x_{n}, \alpha\right)$. Now $T z_{n}=$ $T\left(\Phi\left(x_{0}, x_{n}, \alpha\right)\right)=\Phi\left(T x_{0}, T x_{n}, \alpha\right) \rightarrow \Phi\left(T x_{0}, z, \alpha\right)=y$, and $d\left(x_{0}, z_{n}\right)=\alpha d\left(x_{0}, x_{n}\right)=$ $\gamma^{-1} d^{\prime}\left(y, T x_{0}\right) d\left(x_{0}, x_{n}\right)=2 d^{\prime}\left(y, T x_{0}\right) d\left(x_{0}, x_{n}\right) /\left(\varepsilon^{\prime \prime}+d^{\prime}\left(y, T x_{0}\right)\right) \leqq\left(2 k / \varepsilon^{\prime \prime}\right) d^{\prime}\left(y, T x_{0}\right)$.

We now pause for a brief recapitulation. Given a point $x_{0}$, if there is an integer $n$ and a $\lambda>0$ such that $S\left(T x_{0}, \lambda\right)$ is round and $S\left(T x_{0}, \lambda\right) \subset \overline{T\left(S\left(x_{0}, n\right)\right)}$, then given $z \in S\left(T x_{0}, \lambda\right)$ and $\eta>0$ there is an $x \in X$ with $d\left(x, x_{0}\right) \leqq(2 n / \lambda) d^{\prime}\left(z, T x_{0}\right)$ and $d^{\prime}(T x, z)<\eta$. We now show that a similar approximation can be performed uniformly in a neighbourhood of $x_{0}$.

Since $T$ is continuous at $x_{0}$, there is a $\delta>0$ such that $d\left(x_{0}, y\right)<$ $\delta \Rightarrow d^{\prime}\left(T x_{0}, T y\right)<\lambda / 2$. Let $y \in S\left(x_{0}, \min (\delta, n)\right)$. If $z \in S(T y, \lambda / 2)$, then $d^{\prime}\left(z, T x_{0}\right) \leqq d^{\prime}(z, T y)+d^{\prime}\left(T y, T x_{0}\right)<\lambda$, so

$$
S(T y, \lambda / 2) \subset S\left(T x_{0}, \lambda\right) \subset \overline{T\left(S\left(x_{0}, n\right)\right)} .
$$

Now $z \in S\left(x_{0}, n\right) \Rightarrow d(z, y) \leqq d\left(z, x_{0}\right)+d\left(x_{0}, y\right)<2 n$, so $S\left(x_{0}, n\right) \subset S(y, 2 n)$, and so $S(T y, \lambda / 2) \subset \overline{T(S(y, 2 n))}$. Since $S(T y, \lambda / 2) \subset S\left(T x_{0}, \lambda\right), S(T y, \lambda / 2)$ is round, and by repeating the previous computation, given $z \in$ $S(T y, \lambda / 2)$ and $\eta>0$, there is an $x \in X$ with

$$
d(x, y) \leqq[2(2 n) /(\lambda / 2)] d^{\prime}(z, T y)=\left(\frac{8 n}{\lambda}\right) d^{\prime}(z, T y)
$$

and $d^{\prime}(T x, z)<\eta$.

Therefore, for any $x_{0} \in X$, there are constants $\delta, \varepsilon$ and $M$ such that $d\left(x_{0}, y\right)<\delta, d^{\prime}(z, T y)<\varepsilon$ and $\eta>0 \Rightarrow$ there is an $x \in X$ such that $d(x, y) \leqq M d^{\prime}(z, T y)$ and $d^{\prime}(T x, z)<\eta$. 
Let $\delta, \varepsilon$, and $M$ be defined as above. We now show $T$ is open by showing $T\left(S\left(x_{0}, \rho\right)\right)$ contains the sphere $S\left(T x_{0}, \alpha\right)$, where $\alpha=$ $1 / 2 \min (\varepsilon, \delta / 2 M, \rho / 2 M)$. For $n=1,2, \cdots$ let

$$
\eta_{n}=\frac{1}{2} \min \left(\varepsilon, \delta / 2^{n+1} M, \rho / 2^{n+1} M\right) .
$$

Let $z \in S\left(T x_{0}, \alpha\right)$.

Since $d^{\prime}\left(z, T x_{0}\right)<\varepsilon$, choose $x_{1} \in X$ with

$$
d\left(x_{0}, x_{1}\right) \leqq M d^{\prime}\left(T x_{0}, z\right), d^{\prime}\left(T x_{1}, z\right)<\eta_{1} .
$$

Now $d\left(x_{0}, x_{1}\right) \leqq M d^{\prime}\left(T x_{0}, z\right)<\alpha M<\delta$ and $d^{\prime}\left(T x_{1}, z\right)<\eta_{1}<\varepsilon$, so we can choose $x_{2} \in X$ with $d\left(x_{1}, x_{2}\right) \leqq M d^{\prime}\left(z, T x_{1}\right)$ and $d^{\prime}\left(T x_{2}, z\right)<\eta_{2}$ Inductively, assume we have chosen $x_{2}, \cdots, x_{n}$ such that, for $2 \leqq j \leqq n$, $d\left(x_{j-1}, x_{j}\right) \leqq M d^{\prime}\left(z, T x_{j-1}\right)$ and $d^{\prime}\left(T x_{j}, z\right)<\eta_{j}$. Now $d\left(x_{0}, x_{n}\right) \leqq d\left(x_{0}, x_{1}\right)+$ $d\left(x_{1}, x_{2}\right)+\cdots+d\left(x_{n-1}, x_{n}\right) \leqq M d^{\prime}\left(T x_{0}, z\right)+M \sum_{j=1}^{n-1} d^{\prime}\left(z, T x_{j}\right)<M \alpha+$ $M \sum_{j=1}^{n-1} \eta_{j}<M(\delta / 2 M)+M \sum_{j=1}^{n-1}\left(\delta / 2^{j+1} M\right)=\sum_{j=0}^{n-1} \delta / 2^{j+1}<\delta$, and also $d^{\prime}\left(T x_{n}, z\right)<\eta_{n}<\varepsilon$, so we can choose $x_{n+1} \in X$ with $d\left(x_{n}, x_{n+1}\right) \leqq M d^{\prime}\left(z, T x_{n}\right)$ and $d^{\prime}\left(T x_{n+1}, z\right)<\eta_{n+1}$.

If $1 \leqq n<m$, then

$$
\begin{aligned}
d\left(x_{n}, x_{m}\right) & \leqq d\left(x_{n}, x_{n+1}\right)+\cdots+d\left(x_{m-1}, x_{m}\right) \\
& \leqq M \sum_{j=n}^{m-1} d^{\prime}\left(z, T x_{j}\right)<M \sum_{\jmath=n}^{m-1} \eta_{j}<\delta / 2^{n} ;
\end{aligned}
$$

by completeness there is an $x \in X$ such that $x_{n} \rightarrow x$. Since $\eta_{n} \rightarrow 0$, $T x_{n} \rightarrow z$, by continuity $T x_{n} \rightarrow T x$, so $T x=z$. We are done if we can show that $d\left(x_{0}, x\right)<\rho$. For $n \geqq 1, d\left(x_{0}, x\right) \leqq d\left(x_{0}, x_{1}\right)+\cdots+d\left(x_{n+1}, x_{n}\right)+$ $d\left(x_{n}, x\right) \leqq M d^{\prime}\left(T x_{0}, z\right)+M \sum_{j=1}^{n-1} d^{\prime}\left(z, T x_{j}\right)+d\left(x_{n}, x\right)<M \alpha+M \sum_{j=1}^{n-1} \eta_{j}+$ $d\left(x_{n}, x\right)<M(\rho / 3 M)+M \sum_{j=1}^{n-1}\left(\rho / 3 \cdot 2_{j} M\right)+d\left(x_{n}, x\right)$, so, since $x_{n} \rightarrow x$, we have $d\left(x_{0}, x\right) \leqq \rho / 3+\sum_{j=1}^{\infty}\left(\rho / 3 \cdot 2^{j}\right)=2 o / 3<\rho$, completing the proof.

If the hypotheses seem somewhat cumbersome, it should be rememebered that the Uniform Boundedness and Open Mapping Theorems in linear topological spaces also place heavy restrictions on the topologies involved.

We conclude by making some remaks relevant to the Closed Graph Theorem, one of the most useful consequences of the Open Mapping Theorem. Call a space $(X, d)$ which satisfies all the hypothesis listed in Theorem 1 a normal space. Given two normal spaces $(X, d)$ and $\left(Y, d^{\prime}\right)$, if we can show that the product $\left(X \times Y, d^{\prime \prime}\right)$ (where $d^{\prime \prime}\left(\left(x_{1}, y_{1}\right)\right.$, $\left.\left(x_{2}, y_{2}\right)\right)=d\left(\left(x_{1}, x_{2}\right)+d^{\prime}\left(y_{1}, y_{2}\right)\right)$ is normal, standard techniques (for example, [1] p. 100 and p. 116) will prove that, if $T: X \rightarrow Y$ is affine with closed graph, then $T$ is continuous.

The verification that the product $\left(X \times Y, d^{\prime \prime}\right)$ of normal spaces $(X, d)$ and $\left(Y, d^{\prime}\right)$ follows quickly from the following lemma. 
Lemma 2. $\left(X \times Y, d^{\prime \prime}\right)$ is a space with unique segments.

Proof. Given a path $\lambda$ in $X$ and a path $\gamma$ in $Y$, define $\lambda \times \gamma(t)=$ $(\lambda(t), \gamma(t))$, and if $\mu$ is a path in $X \times Y$, define $\pi_{Y}(\mu)$ and $\pi_{Y}(\mu)$ by $\mu(t)=$ $\left(\pi_{X}(\mu)(t), \pi_{Y}(\mu)(t)\right)$. Given a path $\rho$ of finite length, its length will be denoted by $l(\rho)$, and the variation of $\rho$ over a partition $P$ of $[0,1]$ will be denoted by $l(\rho ; P)$. We assert that, if $\pi_{x}(\mu)$ and $\pi_{Y}(\mu)$ have finite length, then $l(\mu)=l\left(\pi_{X}(\mu)\right)+l\left(\pi_{Y}(\mu)\right)$. Since $l(\mu ; P)=l\left(\pi_{X}(\mu) ; P\right)+$ $l\left(\pi_{Y}(\mu) ; P\right)$, clearly $l(\mu) \leqq l\left(\pi_{X}(\mu)\right)+l\left(\pi_{Y}(\mu)\right)$. The reverse inequality is proved by choosing $\varepsilon>0$, finding partitions $P_{X}$ and $P_{Y}$ which approximate $l\left(\pi_{X}(\mu)\right)$ and $l\left(\pi_{Y}(\mu)\right)$ to within $\varepsilon / 2$, letting $P$ denote the common refinement of $P_{X}$ and $P_{Y}$ will yield $l(\mu)+\varepsilon>l\left(\pi_{X}(\mu)\right)+l\left(\pi_{Y}(\mu)\right)$. If $\lambda$ and $\gamma$ are geodesics in $X$ and $Y$ respectively, then $l(\lambda \times \gamma)=$ $l(\lambda)+l(\gamma)$. If $\mu$ is a path in $X \times Y$ with $l(\mu)<l(\lambda \times \gamma)$, then $l\left(\pi_{X}(\mu)\right)+l\left(\pi_{Y}(\mu)\right)<l(\lambda)+l(\gamma) \Rightarrow$ either $l\left(\pi_{X}(\mu)\right)<l(\lambda)$ or $l\left(\pi_{Y}(\mu)\right)>$ $l(\gamma)$, a contradiction. Similarly, if $l(\mu)=l(\lambda \times \gamma)$, then $l\left(\pi_{X}(\mu)\right)=l(\lambda)$ and $l\left(\pi_{Y}(\mu)\right)=l(\gamma)$, which shows that $\pi_{X}(\mu)=\lambda$ and $\pi_{Y}(\mu)=\gamma$, so $\mu=\lambda \times \gamma$ and geodesics in $\left(X \times Y, d^{\prime \prime}\right)$ are unique.

In conclusion, it is interesting to note that the hypothesis that $S\left(x_{0}, \varepsilon\right)$ is convex is clearly analogous to the assumption that a linear topological space is locally convex. It is clear that many standard concepts in linear topogical space theory are geodesically defined (such as an absorbing neighbourhood), and consequently are easily translated into the theory of spaces with unique segments. In addition to the question of which theorems from normed linear spaces hold in suitably restricted spaces with unique segments, the following problem arises quite naturally: is there a category whose objects include both linear topological spaces and spaces with unique segments, and whose morphisms are the "affine" maps? A reasonable condidate would be topological spaces $X$ with a geodesic-like structure such as a map $\Phi: X \times$ $X \times I \rightarrow X$ (where $I=[0,1]$ ) satisfying such conditions as (1) for fixed $x, y \in X, \Phi(x, y, t)$ is a continuous function of $t,(2) \Phi(x, x, t)=x$, and (3) $\Phi(\Phi(x, y, s), \Phi(x, y, t), u)=\Phi(x, y,(1-u) s+u t)$. Some work has been done on spaces with convexity structures, but from a purely algebraic standpoint. It would be extremely interesting to find out to what extent such theorems as the Open Mapping Theorem and the Uniform Boundedness Theorem can be generalized.

\section{REFERENCES}

1. W. Rudin, Real and Complex Analysis, New York, McGraw-Hill, 1966.

2. J. Stein, Two uniform boundedness theorems, Pacific J. Math., 38 (1971), 251-260.

Received October 28, 1970.

University of CALifornia, Los ANgeles 


\title{
PACIFIC JOURNAL OF MATHEMATICS
}

\section{EDITORS}

\author{
H. SAMELSON \\ Stanford University \\ Stanford, California 94305 \\ C. R. HobBY \\ University of Washington \\ Seattle, Washington 98105
}

J. DugundJI

Department of Mathematics

University of Southern California

Los Angeles, California 90007

RICHARD ARENS

University of California

Los Angeles, California 90024

\section{ASSOCIATE EDITORS}
E. F. BECKENBACH
B. H. NeumanN
F. WOLF
K. YOSHIDA

\section{SUPPORTING INSTITUTIONS}

\author{
UNIVERSITY OF BRITISH COLUMBIA \\ CALIFORNIA INSTITUTE OF TECHNOLOGY \\ UNIVERSITY OF CALIFORNIA \\ MONTANA STATE UNIVERSITY \\ UNIVERSITY OF NEVADA \\ NEW MEXICO STATE UNIVERSITY \\ OREGON STATE UNIVERSITY \\ UNIVERSITY OF OREGON \\ OSAKA UNIVERSITY
}

\author{
UNIVERSITY OF SOUTHERN CALIFORNIA \\ STANFORD UNIVERSITY \\ UNIVERSITY OF TOKYO \\ UNIVERSITY OF UTAH \\ WASHINGTON STATE UNIVERSITY \\ UNIVERSITY OF WASHINGTON
AMERICAN MATHEMATICAL SOCIETY
NAVAL WEAPONS CENTER

The Supporting Institutions listed above contribute to the cost of publication of this Journal, but they are not owners or publishers and have no responsibility for its content or policies.

Mathematical papers intended for publication in the Pacific Journal of Mathematics should be in typed form or offset-reproduced, (not dittoed), double spaced with large margins. Underline Greek letters in red, German in green, and script in blue. The first paragraph or two must be capable of being used separately as a synopsis of the entire paper. The editorial "we" must not be used in the synopsis, and items of the bibliography should not be cited there unless absolutely necessary, in which case they must be identified by author and Journal, rather than by item number. Manuscripts, in duplicate if possible, may be sent to any one of the four editors. Please classify according to the scheme of Math. Rev. Index to Vol. 39. All other communications to the editors should be addressed to the managing editor, Richard Arens, University of California, Los Angeles, California, 90024.

50 reprints are provided free for each article; additional copies may be obtained at cost in multiples of 50 .

The Pacific Journal of Mathematics is published monthly. Effective with Volume 16 the price per volume (3 numbers) is $\$ 8.00$; single issues, $\$ 3.00$. Special price for current issues to individual faculty members of supporting institutions and to individual members of the American Mathematical Society: $\$ 4.00$ per volume; single issues $\$ 1.50$. Back numbers are available.

Subscriptions, orders for back numbers, and changes of address should be sent to Pacific Journal of Mathematics, 103 Highland Boulevard, Berkeley, California, 94708.

\section{PUBLISHED BY PACIFIC JOURNAL OF MATHEMATICS, A NON-PROFIT CORPORATION}

Printed at Kokusai Bunken Insatsusha (International Academic Printing Co., Ltd.), 270, 3chome Totsuka-cho, Shinjuku-ku, Tokyo 160, Japan. 


\section{Pacific Journal of Mathematics}

\section{Vol. 40, No. $2 \quad$ October, 1972}

Louis I. Alpert and L. V. Toralballa, An elementary definition of surface area in $E^{n+1}$ for smooth surfaces...........................

Eamon Boyd Barrett, A three point condition for surfaces of constant mean curvature........................................

Jan-Erik Björk, On the spectral radius formula in Banach algebras ....... 279

Peter Botta, Matrix inequalities and kernels of linear transformations . . . . 285

Bennett Eisenberg, Baxter's theorem and Varberg's conjecture ........... 291

Heinrich W. Guggenheimer, Approximation of curves .............. 301

A. Hedayat, An algebraic property of the totally symmetric loops associated with Kirkman-Steiner triple systems ....................... 305

Richard Howard Herman and Michael Charles Reed, Covariant representations of infinite tensor product algebras ................

Domingo Antonio Herrero, Analytic continuation of inner

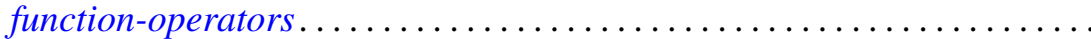

Franklin Lowenthal, Uniform finite generation of the affine group......... 341

Stephen H. McCleary, 0-primitive ordered permutation groups .......... 349

Malcolm Jay Sherman, Disjoint maximal invariant subspaces .......... 373

Mitsuru Nakai, Radon-Nikodým densities and Jacobians .............. 375

Mitsuru Nakai, Royden algebras and quasi-isometries of Riemannian manifolds. . .

Russell Daniel Rupp, Jr., A new type of variational theory sufficiency

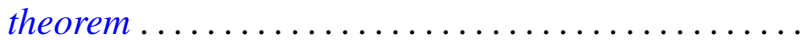

Helga Schirmer, Fixed point and coincidence sets of biconnected multifunctions on trees..........................

Murray Silver, On extremal figures admissible relative to rectangular

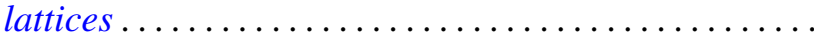

James DeWitt Stein, The open mapping theorem for spaces with unique segments ...

Arne Stray, Approximation and interpolation

Donald Curtis Taylor, A general Phillips theorem for $C^{*}$-algebras and some applications

Florian Vasilescu, On the operator $M(Y)=T Y S^{-1}$ in locally convex algebras...

Philip William Walker, Asymptotics for a class of weighted eigenvalue problems...

Kenneth S. Williams, Exponential sums over $\mathrm{GF}\left(2^{n}\right)$. 